Review article

Central Eur J Paed 2018;14(1):37-46

DOI $10.5457 / \mathrm{p} 2005-114.197$

\title{
How to grow up with chronic kidney disease?
}

\author{
Amira Peco-Antić \\ University Children'Hospital \\ Belgrade, Serbia \\ Correspondence: \\ amirapecoantic@yahoo.com \\ Tel.: + 381603289191 \\ Fax.: + 381112684672
}

Received: October 22, 2017

Accepted: February 3, 2018

Key words: Chronic renal failure - Children - Hemodialysis - Kidney transplantation Transition.

\section{Introduction}

Progress in medicine has transformed endstage renal disease (ESRD) in children from a historically fatal disease of childhood to adult chronic kidney disease (CKD) with an expected survival more than 50 years $(1,2)$. Of course, the survival of ESRD patients differs in relation to the age of the patients and the modalities of treatments; children with severe renal disease are at higher risk of death in the first 2 years of life (3) and the average
The aim of this paper was to provide information on the best practice to allow children with chronic kidney disease (CKD) to attain normal adult physical and psychological development as well as social rehabilitation. Growth and development of children with CKD is associated with many problems that arise from the primary disease, the stage of CKD and complications of the disease and therapy. Only comprehensive treatment, which includes correction of metabolic disorders and anemia, normalization of growth and blood pressure, management of mineral and bone disease, psychosocial rehabilitation and renal replacement therapy by dialysis or renal transplantation in end-stage renal disease, can allow these patients to grow up. A multidisciplinary care team, including pediatricians, psychologists, dieteticians and social workers, can help to address these important needs of both patients and their caregivers. Adolescents with CKD, and especially those with end-stage renal disease (ESRD), face many additional challenges concerning their physical, emotional, educational and social demands, and they also need to take responsibility for their own care in order to achieve a good outcome and longer survival. The well-organized process of transition from pediatric to adult care institutions is important to raise the level of self-confidence, self-control and treatment compliance in adolescent patients. Conclusion - Pediatric CKD has many long-term consequences, of which treatment is best carried out by a multidisciplinary team. Kidney transplantation is the best therapeutic option for children with ESRD. The transition of adolescents from a pediatric to an adult institution must be gradual, and well prepared. life expectancy for transplanted children with a functioning graft is higher compared with those remaining on dialysis (4). Prior to the second half of the $20^{\text {th }}$ century, the majority of children with ESRD were growth retarded, malnourished, edematous and pale, with rickety deformities and reduced physical and mental capacity, and they looked unhappily chronically ill. However, in the present day children with well-managed ESRD, thanks to comprehensive multidisciplinary pediatric treatment, have much better quality of 
life and look well, often not different from their healthy peers. Nevertheless, the transition of an adolescent patient from pediatric to adult nephrologists is still a major problem with possible negative consequences because of the disruption of continuity in the earlier pediatric treatment (5-9). The problem of transition deserves a great deal of attention.

This paper aims to provide information on the best practice to allow children with CKD to attain normal adult physical and psychological development, as well as social rehabilitation. Special attention is paid to the process of transition.

\section{Chronic kidney disease, demographic characteristics}

Chronic kidney disease is defined as a structural and/or functional impairment of the kidney, which lasts for at least three months, and is manifested by one or more disturbances in the composition of the blood and / or urine, or abnormalities in the display of morphology and / or renal function, or when the glomerular filtration rate (GFR) is less than $60 \mathrm{ml} / \mathrm{min} / 1.73 \mathrm{~m}^{2}$ (10). Table 1 shows the stages of CKD according to the degree of the residual renal function estimated according to Schwartz's formula (11). Stage, CKD or ESRD is defined as any decrease with estimated GFR below $15 \mathrm{ml} / \mathrm{min} / 1.73$ $\mathrm{m}^{2}$, and/or as the need to start renal replacement therapy (10).
This classification does not apply to children under 2 years due to the physiological immaturity of renal function, but a similar one for children younger than 2 years may be created, analogous to this classification, taking into account their reference values for GFR (12). Children born with hereditary renal diseases or congenital anomalies of the urinary tract are not required to meet the condition of kidney disease duration of at least 3 months and are considered to have CKD from birth (13).

The incidence of CKD is best known in its terminal stage when it is the well diagnosed due to the expression of severe multiorgan symptoms. The median incidence of ESRD in children ages 0-19 years in the world amounts to 9 per year per million of the child population (pmcp), while the prevalence ranges from 18 to 100 pmcp (13). However, ESRD is just the tip of the iceberg because it constitutes only a few percent of the total CKD. The incidence and prevalence of CKD stages ${ }_{2-5}$ in children in Europe has been variously reported in a range from 7.7 to 14.3 and from 56 to 96.1 pmcp (13-19), respectively. These figures are certainly underestimated. Both incidence and prevalence increase with age and are more common in male children $(14,19)$.

In contrast to adult $\mathrm{CKD}$, which is predominately caused by diabetic nephropathy, hypertension, and autosomal dominant polycystic kidney disease, the main causes of

\section{Table 1. Classification of chronic kidney disease}

\begin{tabular}{lll}
\hline Stage & eGFR, $\mathrm{ml} / \mathrm{min} / 1,73 \mathrm{~m}^{2}$ & Description \\
\hline 1. & $\geq 90$ & Normal or increased eGRF \\
2. & $60-89$ & Mild decrease of eGRF \\
3. & $30-59$ & Moderate decrease of eGRF=CRF \\
4. & $15-29$ & Severe decrease of eGRF=preterminal CRF \\
5. & $<15$ (or RRT) & ESRD \\
\hline
\end{tabular}

eGFR=Estimated glomerular filtration rate according to Schwartz's formula (11); CRF=Chronic renal failure; ESRD=End-stage renal disease; RRT=Renal replacement therapy. 
pediatric $\mathrm{CKD}$ are congenital anomalies of the kidney and urinary tract (CAKUT), accounting for approximately 50\%, followed by hereditary nephropathies and glomerulonephritis $(13,14,19)$. CAKUT is more common in younger children, while the occurrence of glomerulopathy (predominantly focal segmental glomerulosclerosis) increases from the second decade of life and is highest in $\operatorname{ESRD}(12,20)$. Less common but very important causes of childhood CKD are autosomal recessive polycystic kidney diseases and hemolytic uremic syndrome.

The life expectancy of children with CKD is longer than in adult patients; 10-year survival rate of adolescents with ESRD is about $80 \%$, but still mortality is 30 times higher than that of healthy peers $(1,20)$.

\section{Progression of chronic kidney disease}

Often silent for a long time, $\mathrm{CKD}$ can evolve to chronic renal failure (CRF) or even ESRD. The progression of CKD is variable and depends on the underlying disease, the severity of the initial injury, genetic background, and the presence of additional risk factors (10). Data from the NAPRTCS on more than 4,000 children with CKD stages ${ }_{2-4}$ showed a progression rate to ESRD of $17 \%$ at 1 year and $39 \%$ at 3 years following registration, with a median time to ESRD of 4.5 years (21). Progression is the most rapid during puberty and adolescence $(14,19)$

The mechanism of CKD progression is very complex and has not been sufficiently clarified. Presently, two main mechanisms are discussed: (1) the loss of nephrons leads to compensatory mechanisms in the remaining nephrons (glomerular hypertension, hyperfiltration, hypertrophy) which increase their vulnerability to any further challenge (overload hypothesis); and (2) a proteinuric glomerular disease leads to tubulointerstitial inflammation and fibrosis, accounting for the further deterioration of renal function (fibro- sis hypothesis) (22). In general, the extent of tubulointerstitial fibrosis is the best predictor of kidney survival, irrespective of the underlying disease (23).

A lower level of kidney function at presentation, higher levels of proteinuria, and hypertension are well known clinical markers for a more rapid decline in GFR (23, 24). Other reported risk factors associated with $\mathrm{CKD}$ progression include: low birth weight or prematurity, increased uric acid concentration, lead or heavy metals, hyperlipidemia, metabolic acidosis, oxidative stress, and disorders of bone and mineral metabolism (CKD-MBD) (25). An inherited predisposition for $\mathrm{CKD}$ progression may be in the form of monogenetic mutations, single nucleotide polymorphisms, and epigenetic modifications of the genome (DNA methylation, histone modification, or RNA interference) influenced by environmental factors (26). Nowadays, more than 200 genes are clearly recognized as causative of the most common etiological categories of $\mathrm{CKD}$ in children (CAKUT, steroid resistant nephritic syndrome, and ciliopathies) (27).

\section{Comorbidity of chronic kidney disease}

Clinical manifestations of CKD are mainly dependent on the primary renal disease and the degree of residual GFR. Thus, a decrease in GFR increases the number and severity of symptoms culminating in multi-organ failure (uremia) in ESRD. CKD stages $\geq 3$ are characterized by water-electrolyte disturbances, metabolic acidosis, CKD-MBD, growth retardation, hypertension and cardiovascular disorders, anemia and other hematologic, endocrinological, immunological and neurological complications. Disorders of water balance are due to the reduced ability to concentrate urine, and are reflected in the early appearance of polyuria and polydipsia. Nocturnal enuresis may be due to nocturnal polyuria. 
Usually serum concentrations of sodium and potassium are maintained within the reference values even up to ESRD. However, under the heavy load of potassium and/or increased catabolism (infections, hemolysis, trauma...), as well as the uncontrolled use of medicaments that inhibit the activity of mineralocorticoids (ACE inhibitors, spironolactone), hyperkalemia may be life-threatening. Metabolic acidosis adversely affects growth, cardiovascular and bone systems, and accelerates the progression of $\mathrm{CKD}$.

CKD-MBD is a complex multisystem disorder affecting not only the bones (modeling, remodeling, and bone growth) but also inducing vascular and soft tissue calcifications (28). It is the consequence of the disturbed homeostasis of calcium and phosphorous due to interfering disorders in the effects of fibroblast growth factor (FGF23), kidney, parathyroid gland, intestinal tract and bone along with decreased expression and sensitivity of calcium sensing receptors (CaSR), and decreased number of vitamin D receptors (VDR). The clinical manifestations of CKD-MBD include bone pain, myopathy, rickets, bone deformations, fractures and cardiovascular calcifications, in addition to poor growth.

Anemia is a frequent complication of CKD. Its prevalence in CKD patients is in inverse relationship to GFR. It increases from $30 \%$ in CKD stage 1 to 2 to $93 \%$ in CKD stage 4-5 (29). Data from CKiD showed that there is a statistically significant decline in hemoglobin concentrations by -0.3 grams/dl for each $5 \mathrm{ml} / \mathrm{min} / 1.73 \mathrm{~m}^{2}$ decrease in GFR below a threshold GFR of $43 \mathrm{ml} / \mathrm{min} / 1.73 \mathrm{~m}^{2}$ (30). Anemia is normochromic and normocytic, with a low reticulocyte count. It is the consequence of the reduced synthesis of erythropoietin $(90 \%$ is normally produced in the kidney), the shortened erythrocyte survival, unresponsiveness of bone marrow to erythropoietin (inhibitory effects of uremic toxins, bone marrow fibrosis), reduced iron, folic acid and vitamin B 12, increased blood loss, mainly through the gastrointestinal tract and/or during hemodialysis, and some medications (e.g., angiotensin converting enzyme inhibitors (ACEI) and angiotensin receptor blockers (ARB). In addition, increased synthesis of hepcidin, due to chronic inflammation, blocks macrophage iron release and intestinal iron absorption. Anemia has an adverse effect on the cardiovascular system, aerobic capacity, the overall sense of wellbeing, and cognition. Treatment of anemia by blood transfusions results in human leukocyte antigen sensitization, thus decreasing the chance for successful kidney transplantation. The introduction of recombinant human erythropoietin ( $\mathrm{rHuEPO}$ ) to the treatment regimen three decades ago revolutionized the therapy and significantly decreased the need for repeated blood transfusions and exposure to the associated risks. Darbopoetin alpha is a reasonable alternative to $\mathrm{rHuEPO}$ in the treatment of anemia in pediatric CKD patients, due to its clinical efficacy, convenience of use, patient compliance and tolerability (31).

Growth failure is the most visible feature of CKD. Almost a third of CKD patients have severe growth failure, with height standard deviation less than -3 (32). Children with hereditary nephropathy have worse growth retardation (32). The main CKD stunting causal factors are: inadequate protein and calory intake, increased loss of water and electrolytes in children with polyuria and natriuresis, anemia, metabolic acidosis, renal osteodystrophy, and resistance to hormones that affect growth. Growth hormone (GH) resistance is due to the low $\mathrm{GH}$ receptor density in target tissues, postreceptor (JAK/ STAT) disorders, and due to the reduced concentration of the free fraction of the insulin growth factor (IGF-1), since the reduced clearance of proteins that bind to IGF-1. Furthermore, the expected acceleration of pubertal grow in CRF is only $65 \%$ of normal due 
to delayed onset of puberty (by an average of 2.5 years) and its shortened duration, which are explained by disorder of the gonadotrophin hormone secretion in the hypothalamus $(\mathrm{GnRH})$. An additional adverse effect on growth may be the result of the use of some drugs (corticosteroids). Growth retardation has a negative impact on morbidity and mortality (33), quality of life (34) and psychosocial rehabilitation (35). Although their final height remains suboptimal in children with ESRD (median of $168 \mathrm{~cm}$ in boys and 155 $\mathrm{cm}$ in girls), it has consistently improved over time with better treatment that includes nutritional and metabolic control and therapy with recombinant human growth hormone (rhGH) $(36,37)$.

Hypertension (HTN) is the most common complication of CKD/ESRD. Its prevalence is the highest in ESRD ( $>90 \%)$. It is most common in glomerulonephritis (88\%), followed by renal scarring, hemolytic-uremic syndrome and polycystic kidney disease. The pathogenetic factors are: hypervolemia due to retention of salt and water, the activation of rennin angiotensin aldosterone system (RAAS), the enhanced activity of the sympathetic nervous system, the predominance of endothelial vasoactive factors and secondary hyperparathyroidism, or additional adverse effects of medications (corticosteroids, cyclosporine..). Renal HTN is often unrecognized (nocturnal or masked) and untreated (24). It is best revealed by 24-hour ambulatory blood pressure monitoring. Untreated hypertension causes cardiovascular and cerebrovascular complications, and accelerates the progression of CKD (24).

Cardiovascular complications (CVD) are the leading cause of death in children with ESRD (38). They are the consequences of hypertension, hypervolemia, anemia, CKD$\mathrm{MBD}$, chronic acidosis, increased activity the sympathetic nervous system and uremic toxins. The most common form of CVD is eccentric or concentric left ventricular hy- pertrophy (LVH), but much more dangerous is dilated cardiomyopathy with consequent congestive heart failure and arrhythmias.

\section{CKD treatment}

More intensive therapy is required to slow the progression of CKD and to treat its consequences in children compared to adults. The last decade has witnessed enormous achievements in this field (39). In addition to standard renoprotective therapy that works by normalization of blood pressure, proteinuria, hyperphosphataemia, anemia and hyperuricemia, new drugs offer great hope. According to the ESCAPE trial data, strict blood pressure control $\left(\sim 5 \mathrm{o}_{\mathrm{th}}\right.$ percentile) retards progression of $\mathrm{CKD}$ in children, irrespective of the type of underlying kidney disease (24). Vitamin D may also promote renoprotection by suppressing renin transcription through cross-talk between RAAS and vitamin D- FGF-23-Klotho pathways (40). In line with the latest findings on the role of inflammation in the progression of $\mathrm{CKD}$, therapeutic blockade of leucocyte chemokine receptors inhibits secretion of the proinflammatory, proapoptotic and profbrotic cytokines that perpetuate renal tissue destruction (41). The role of the gut as a major source of inflammation adds also a novel therapeutic tool, healthy nutrition, to delay CKD progression.

Therapeutic plans for progressive CKD must be formulated by a multidisciplinary team of pediatric specialists to address the clinical parameters of growth, anemia and osteodystrophy management, cardiovascular health, nutritional adequacy, education, cognitive development, quality of life, preparation for transplantation, and transition to adult care (42).

Acidosis is treated with sodium bicarbonate or sodium citrate with target serum bicarbonate levels $>22 \mathrm{mmol} / \mathrm{l}$. If the child is not oliguric, it is a not necessary to restrict 
liquids. Sodium intake depends on the primary renal disease. Children with congenital renal dysplasia, polycystic kidney disease and nephronophthisis lose sodium in the urine and therefore need a supplement salt. In contrast, children with chronic glomerular diseases should be instructed to restrict salt for better control of blood pressure. For children with $\mathrm{CKD}$, caution is needed with the intake of foods that are rich in potassium.

The initial therapeutic method for CKDMBD is to limit the intake of phosphate in food. It is usually necessary to add calciumfree phosphate binders. After normalization of phosphataemia vitamin $\mathrm{D}$, such as 1-hydroxycholecalciferol (alfakalcidiol) or 1.25 dihidroksiholekalciferol (calcitriol), is introduced to maintain normal levels of PTH in $\mathrm{CKD}_{2-3}$, while in $\mathrm{CKD}_{4-5}$ two to three times higher values than normal are required (due to the resistance of target tissues to the PTH). In the most severe cases calcimimetics could be applied or subtotal parathyroidectomy is performed.

Anemia is treated with erythropoietin (275 U/kg to $350 \mathrm{U} / \mathrm{kg}$ per week for infants, to $200-250 \mathrm{U} / \mathrm{kg}$ per week for older children), iron intake and vitamins, including folic acid and vitamin C.

In children who are small for age, it is first required to normalize nutrition, correct acidosis, and cure CKD-MBD. To meet the nutritional needs of children with chronic renal failure, it is often necessary to apply energy and essential amino acid supplements and, in cases of severe anorexia, vomiting and other problems in food intake, it is necessary to insert a nasogastric or transpiloric probe, or perform gastrostomy. If at least 3 to 6 months after normalization of nutrition and metabolic complications there is no improvement in growth (measured by $\mathrm{HtSDS}$ $<-1.88$, and the rate of growth velocity of less than -2 SD), it is necessary to consider the introduction of recombinant growth hormone (rhGH).
The results of the ESCAPE trial emphasize the importance of HTN as both a risk factor and a treatment target for pediatric CKD progression (24). Target BP in children with $\mathrm{CKD}$ is $<75^{\text {th }}$ percentile in children without proteinuria, and $\leq 50^{\text {th }}$ percentile in children with proteinuria. For children who had severe growth retardation $(\mathrm{HtSDS}<3$ ) blood pressure percentiles are determined in relation to the percentile for height, regardless of chronological age (the age correspond to $50^{\text {th }}$ for height). In patients with $\mathrm{CKD}_{1-4}$ the drugs of choice for HTN are ACEI/ARB, while in ESRD hypervolemia should be eliminated. Successful transplantation eliminates or improves risk factors for cardiovascular disease, and improves survival.

\section{Renal replacement therapy}

Survival of children with ESRD is possible due to renal replacement therapy (RRT) by dialysis or kidney transplantation. Mortality in pediatric patients treated with RRT in Europe during the period from 2009 to 2011 was 55-fold higher than that of the general EU pediatric population (43). Overall survival at 4 years was $93.7 \%$, with the poorest survival in patients aged $0-4$ years, and in patients starting on dialysis. Infections (19.9\%) were the primary cause of death in European pediatric RRT patients (43). According to the K-DOQI guidelines (44) initiation of dialysis should be considered when the GFR falls below $14 \mathrm{ml} / \mathrm{min} / 1.73 \mathrm{~m}^{2}$ and is strongly recommended when the GFR is $<8 \mathrm{ml} /$ $\min / 1.73 \mathrm{~m}^{2}$. However, for deciding when dialysis should be started, the clinical wellbeing of the patient is most important (44).

Usually one pediatric dialysis centre is required per million of the child population ( $\geq 10$ dialysis patients). It should have experience with both hemodialysis (HD) and peritoneal dialysis (PD) in children, as well as providing ongoing support. The best solution is when the pediatric dialysis center is 
close to the pediatric transplant centre. RRT is an expensive treatment. Higher RRT treatment rates in Europe are found in wealthier countries (2.47 pmc/€10 378 GDP per capita, $\mathrm{P}<0.0001)$, among those that tend to spend more on healthcare $(1.45 \mathrm{pmc} / 1.7 \%$ public health expenditure, $\mathrm{P}<0.0001)$, and among countries where patients pay less outof-pocket for healthcare $(-1.29 \mathrm{pmc} / 11.7 \%$ out-of-pocket health expenditure, $\mathrm{P}<0.0001)$ (45).

Peritoneal dialysis consists of solute and water exchange (by diffusion and convective transport) between blood and the dialysis fluid, separated by a semipermeable peritoneal membrane. It is the best RRT modality for children younger than 2 years, and preferred for those under the age of 5 years. Usually PD is performed at home as automatic nighttime dialysis, generally by the parents, and outpatient clinic visits commonly occur on a monthly basis. Individualization of PD schedule prescription depends on body size, dietary intake, metabolic needs, growth rate, risk of clinical and technical complications, and psychosocial rehabilitation. The main PD complication is peritonitis.

Hemodialysis (HD) provides extracorporeal blood purification. Pediatric HD has been improved over the last 2 decades due to the technological progress. The newer machines allow precise control of ultrafiltration by volumetric assessment and continuous blood volume monitoring during the session. Buffered bicarbonate has become a standard technique, there are synthetic more biocompatible membranes, and specific materials available for babies/infants have been developed (46). Conversion from infrequent (4 hours sessions prescribed 3 times per week) to frequent, short daily ( 2 to 3 hours per session prescribed 5 to 6 times per week) or nocturnal hemodialysis ( 6 to 8 hours per session prescribed 5 to 6 times per week during sleep) has been shown to reduce intradialytic and interdialytic hemodynamic instability, and improved BP, CVD and CKD-MBD control (46). The basic factor of successful dialyses is well determined dry weight (defined as body weight at which the patient is as close to euvolemia) estimated by combining clinical assessment, biochemical markers (ANP, BNP, cGMP), inferior vena cava diameter, bioelectric impedance and non-invasive blood volume monitoring.

Kidney transplantation is the optimal treatment for ESRD in children. It enables the best chance of rehabilitation in terms of educational and psychosocial functioning. The surgical procedure is well standardized, with a transperitoneal approach in a child less than $15 \mathrm{~kg}$, or retroperitoneal approach in larger children. Anastomosis sites include the iliac vessels in the retroperitoneal approach, and the inferior vena cava and aorta in the case of a transperitoneal procedure. The main complications of renal transplantation in children are viral infections and post-transplant lymphoproliferative disorder. The benefits of preemptive kidney transplantation are numerous, by avoiding complications of previous dialysis, in terms of the better quality of life and graft survival, especially when done with a living-donor organ.

\section{Transition from pediatric to adult care}

Transition of care for adolescents with kidney disease into an adult setting is critical both for the patients and their caregivers (47). Adolescents and young adults appear to be a particularly high-risk group for problems of non-compliance and associated graft loss. Transplanted adolescents are in the age group with the worst graft survival $(6,47-50)$. An early graft loss is associated with educational, employment, and social failure. It is therefore necessary to promote and organize the process of transition of adolescents from pediatric to adult nephrologists. Unlike a transfer, which actually represents displacement of the patient in a physical sense, transition is 
a planned, scheduled and coordinated process having the aim of preparing and achieving transition of the patient from a pediatric center to a unit for adults, where the patient would be responsible for carrying out the proposed measures of treatment (6).

The International Society of Nephrology and the International Pediatric Nephrology Association in 2011 have jointly drawn up a document with the main guidelines for organization of the transition, and the responsibility for performing this process is shared between the pediatric and adult nephrologists (8). This document emphasizes the need for the transition program from the pediatric to the adult institution to be individualized for each patient, taking into account the level of physical and mental development achieved, and also the goals achieved in education, social and psychosocial development, as well as the structure of possible support (8). Increasing education and awareness about renal diseases in general, and kidney disease in childhood in particular are obligatory measures for both patients and their caregivers, from their very first meeting with pediatric nephrologists. Assessing therapeutic adherence is essential to the patient's clinical follow-up.

The process of transition may proceed in three phases; (1) creation and commencement of a transition plan; (2) educating the patient about self-care and self-responsibility, and (3) the transfer itself, which corresponds to three chronological stages in the patients: preadolescence (12-15 years), adolescence (16-18 years) and young adulthood (19-25 years) (51). Pediatric and adult nephrology teams should be in charge of planning, organizing, implementing and monitoring the transition and transfer of adolescents and young adults. The manager of the transition constitutes one of the mainstays of transition, and has many important roles: to co-ordinate between various specialists in the same hospital, as well as between different hospitals and levels of health care, and to be a link between different professionals within the different levels of care, as well as with the patient and his/her family. The transition manager may be a psychologist or social worker.

\section{Conclusion}

Growing children with CKD have many difficulties due to the underlying kidney disease, comorbidities and complexity of treatment. Stunting is the most visible complication of CKD, while cardiovascular diseases and infections are the most common cause of death. Kidney transplantation, especially preemptively, is the optimal treatment of patients with ESRD. The transition of adolescents from a pediatric to an adult institution is a very important process. It must be well prepared and gradual, individualized, with all the necessary support to overcome the difficulties related to the chronic illness in adolescence. This process is important to raise the level of self-confidence, self-control and treatment compliance in adolescent patients.

Conflict of interest: The author declares that she has no conflict of interest.

\section{References}

1. Ferris ME, Gipson DS, Kimmel PL, Eggers PW. Trends in treatment and outcomes of survival of adolescents initiating end-stage renal disease care in the United States of America. Pediatr Nephrol. 2006;21:1020-6.

2. Ferris ME, Miles JA, Seamon ML. Adolescents and Young Adults with Chronic or End-Stage Kidney Disease. Blood Purif. 2016;41(1-3):205-10.

3. Mekahli D, Shaw V, Ledermann SE, Rees L. Longterm outcome of infants with severe chronic kidney disease. Clin J Am Soc Nephrol. 2010; 5:10-7.

4. Kramer A, Stel VS, Tizard J, Verrina E, Rönnholm $\mathrm{K}$, Pálsson R, et al. Characteristics and survival of young adults who started renal replacement therapy during childhood. Nephrol Dial Transplant. 2009;926-33.

5. Cameron JS. The continued care of pediatric patients with renal disease into adult life. Am J Kidney Dis. 1985;6:91-5. 
6. Forbes TA, Watson AR, Zurowska A, Shroff $\mathrm{R}$, Bakkaloglu S, Vondrak K, et al. Adherence to transition guidelines in European paediatric nephrology units. Pediatr Nephrol. 2014;29:161724.

7. Cameron JS. The continued care of children with renal disease into adult life. Pediatr Nephrol. 2001;16:680-5.

8. Watson AR, Harden P, Ferris M, Kerr PG, Mahan J, Ramzy MF. Transition from pediatric to adult renal services: a consensus statement by the International Society of Nephrology (ISN) and the International Pediatric Nephrology Association (IPNA). Kidney Int. 2011;80:704-7.

9. Watson AR Non-compliance and transfer from paediatric to adult transplant unit. Pediatr Nephrol. 2000;14:469-72.

10. Hogg RJ, Furth S, Lemley KV, Portman R, Schwartz GJ, Coresh J, et al. National Kidney Foundation's Kidney Disease Outcomes Quality Initiative clinical practice guidelines for chronic kidney disease in children and adolescents: evaluation, classification, and stratification. Pediatrics. 2003;111:1416-21.

11. Schwartz GJ, Brion LP, Spitzer A. The use of plasma creatinine concentration for estimating glomerular filtration rate in infants, children, and adolescents. Pediatr Clin North Am. 1987;34:571-90.

12. Kang HG, Choi HJ, Han KH, Kim SH, Cho $\mathrm{HY}$, Cho $\mathrm{MH}$, et al. KNOW-Ped CKD (Korean cohort study for outcomes in patients with pediatric CKD): Design and methods. BMC Nephrol. 2016;17:35.

13. Harambat J, van Stralen KJ, Kim JJ, Tizard EJ. Epidemiology of chronic kidney disease in children. Pediatr Nephrol. 2012;27:363-73.

14. Ardissino G, Daccò V, Testa S, Bonaudo R, ClarisAppiani A, Taioli E, et al. ItalKid Project. Epidemiology of chronic renal failure in children: data from the ItalKid project. Pediatrics. 2003;111:e382-e387.

15. Mong Hiep TT, Ismaili K, Collart F, Van DammeLombaerts R, Godefroid N, Ghuysen MS, et al. Clinical characteristics and outcomes of children with stage 3-5 chronic kidney disease. Pediatr Nephrol. 2010;25:935-40.

16. Deleau J, Andre JL, Briancon S, Musse JP. Chronic renal failure in children: an epidemiological survey in Lorraine (France) 1975-1990. Pediatr Nephrol. 1994;8:472-6.

17. Esbjörner E, Berg U, Hansson S. Epidemiology of chronic renal failure in children: a report from Swe- den 1986-1994. Swedish Pediatric Nephrology Association. Pediatr Nephrol. 1997;11:438-42

18. Bek K, Akman S, Bilge I, Topaloğlu R, Calişkan S, Peru H, et al. Chronic kidney disease in children in Turkey. Pediatr Nephrol. 2009;24:797-806.

19. Peco-Antic A, Bogdanovic R, Paripovic D, Paripovic A, Kocev N, Golubovic E, et al. Epidemiology of chronic kidney disease in children in Serbia. Nephrol Dial Transplant. 2012;27:1978-84.

20. Staples AO, Greenbaum LA, Smith JM, Gipson DS, Filler G, Warady BA, et al. Association between clinical risk factors and progression of chronic kidney disease in children. Clin J Am Soc Nephrol. 2010;5:2172-9.

21. Saran R, Li Y, Robinson B, Ayanian J, Balkrishnan R, Bragg-Gresham J, et al. US Renal Data System 2014 Annual Data Report: Epidemiology of Kidney Disease in the United States. Am J Kidney Dis. 2015;66(1 Suppl1):Svii,S1-305.

22. Kriz W, LeHir M. Pathways to nephron loss starting from glomerular diseases-insights from animal models. Kidney Int. 2005;67:404-19.

23. Zeisberg M, Neilson EG. Mechanisms of tubulointerstitial fibrosis. J Am Soc Nephrol. 2010; 21:1819-34.

24. ESCAPE Trial Group, Wühl E, Trivelli A, Picca S, Litwin M, Peco-Antic A, et al. Strict blood-pressure control and progression of renal failure in children. N Engl J Med. 2009;361:1639-50.

25. Staples A, Wong C. Risk Factors for Progression of Chronic Kidney Disease. Curr Opin Pediatr. 2010; 22:161-9.

26. Harshman LA, Zepeda-Orozco D. Genetic Considerations in Pediatric Chronic Kidney Disease. J Pediatr Genet. 2016;5:43-50.

27. Becherucci F, Roperto RM, Materassi M, Romagnani P. Chronic kidney disease in children. Clin Kidney J. 2016;9:583-91.

28. Kidney Disease: Improving Global Outcomes (KDIGO) CKD-MBD Work Group: KDIGO clinical practice guideline for the diagnosis, evaluation, prevention, and treatment of chronic kidney disease-mineral and bone disorder (CKD-MBD). Kidney Int. 2009; 76(suppl 113):S1-S130.

29. Wong H, Mylrea K, Feber J, Drukker A, Filler G. Prevalence of complications in children with chronic kidney disease according to KDOQI. Kidney Int. 2006;70:585-90. 
30. Fadrowski JJ, Pierce CB, Cole SR, Moxey-Mims M, Warady BA, Furth SL. Hemoglobin decline in children with chronic kidney disease: baseline results from the chronic kidney disease in children prospective cohort study. Clin J Am Soc Nephrol. 2008;3:457-62.

31. Can C, Emre S, Bilge I, Yilmaz A, Şirin A. Comparison of recombinant human erythropoietin and darbepoetin alpha in children. Pediatr Int. 2013;55:296-9.

32. Salević P, Radović P, Milić N, Bogdanović R, Paripović D, Paripović A, et al. Growth in children with chronic kidney disease: 13 years follow up study. J Nephrol. 2014; 27:537-44.

33. Furth SL, Hwang W, Yang C, Neu AM, Fivush BA, Powe NR. Growth failure, risk of hospitalization and death for children with end-stage renal disease. Pediatr Nephrol. 2002;17:450-5.

34. Rosenkranz J, Reichwald-Klugger E, Oh J, Turzer M, Mehls O, Schaefer F. Psychosocial rehabilitation and satisfaction with life in adults with childhood-onset of end-stage renal disease. Pediatr Nephrol. 2005;20:1288-94.

35. Broyer M, Le Bihan C, Charbit M, Guest G, Tete MJ, Gagnadoux MF, et al. Long-term social outcome of children after kidney transplantation. Transplantation. 2004;77:1033-7.

36. Harambat J, Bonthuis M, van Stralen KJ, Ariceta G, Battelino N, Bjerre A, et al. Adult height in patients with advanced CKD requiring renal replacement therapy during childhood. Clin J Am Soc Nephrol. 2014;9(1):92-9.

37. Bizzarri C, Lonero A, Delvecchio M, Cavallo L, Faienza MF, Giordano M, et al. Growth hormone treatment improves final height and nutritional status of children with chronic kidney disease and growth deceleration. J Endocrinol Invest. 2017 Aug 17. doi: 10.1007/s40618-0170745-4.

38. U.S. Renal Data System, USRDS 2010 Annual Data Report: Atlas of Chronic Kidney Disease and End-Stage Renal Disease in the United States, National Institutes of Health, National Institute of Diabetes and Digestive and Kidney Diseases, Bethesda, MD, 2010.

39. Peco-Antic A. What did the Eleventh world kidney day tell us? Paediatrics Today. 2016;12:191-194.

40. Shroff R, Aitkenhead H, Costa N, Trivelli A, Litwin M, Picca S, et al. ESCAPE Trial Group. Normal 25-Hydroxyvitamin D Levels Are Associated with Less Proteinuria and Attenuate Renal Failure Progression in Children with CKD. J Am Soc Nephrol. 2016;314-22.

41. Sharaf El Din UA, Salem MM, Abdulazim DO. Stop chronic kidney disease progression: Time is approaching. World J Nephrol. 2016;5:258-73.

42. Warady BA, Neu AM, Schaefer F. Optimal care of the infant, child, and adolescent on dialysis: 2014 update. Am J Kidney Dis. 2014;64(1):128-42.

43. Chesnaye N, Bonthuis M, Schaefer F, Groothoff JW, Verrina E, Heaf JG, et al. Demographics of paediatric renal replacement therapy in Europe: a report of the ESPN/ERA-EDTA registry. Pediatr Nephrol. 2014;29:2403-10.

44. National Kidney Foundation: K/DOQI clinical practice guidelines for pediatric peritoneal dialysis. Am J Kidney Dis. 2006; 48(1):S98-S130.

45. Chesnaye NC, Schaefer F, Groothoff JW, Caskey FJ, Heaf JG, Kushnirenko S, et al. Disparities in treatment rates of paediatric end-stage renal disease across Europe: insights from the ESPN/ERA-EDTA registry. Nephrol Dial Transplant. 2015;30:1377-85.

46. Fischbach M, Edefonti A, Schröder C, Watson A. The European Pediatric Dialysis Working Group Hemodialysis in children: general practical guidelines Pediatr Nephrol. 2005;20:1054-66.

47. Ingelfnger R. J, Kalantar-Zadeh K, Schaefer F. World Kidney Day 2016. Averting the Legacy of Kidney Disease: Focus on Childhood. Paediatrics Today. 2016;12(1):115-23.

48. Blum RW, Garell D, Hodgman CH, Jorissen TW, Okinow NA, Orr DP, et al. Transition from childcentered to adult health-care systems for adolescents with chronic conditions. A position paper of the Society for Adolescent Medicine. J Adolesc Health. 1993;14(7):570-6.

49. Watson AR, Warady BA. Transition from pediatric to adult-centered care. Dial Transplant. 2011;40(4):156-8.

50. Ferris ME, Mahan JD. Pediatric chronic kidney disease and the process of health care transition. Semin Nephrol. 2009;29(4):435-44.

51. Ariceta G, Camacho JA, Fernández-Obispo M, Fernández-Polo A, Gámez J, García-Villoria J, et al. Transición coordinada del paciente con cistinosis desde la medicina pediátrica a la medicina del adulto. Nefrologia. 2016;36:616-30. 